\title{
Flight Characteristics of a Manned, Low-Speed, Controlled Deep Stall Vehicle
}

\section{Alex G. Sim}

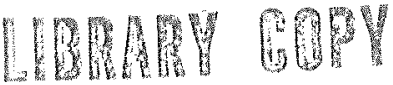

138084

DANOLY RESEARCH CFNTER

MORARY NASA

HWMTON WRGMLA 
NASA Technical Memorandum 86041

\section{Flight Characteristics of a Manned, Low-Speed, Controlled Deep Stall Vehicle}

Alex G. Sim

Ames Research Center, Dryden Flight Research Facility, Edwards, California 93523

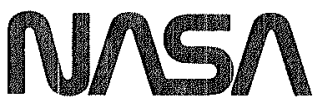

National Aeronautics and

Space Administration

Ames Research Center

Dryden Flight Research Facility

Edwards, California 93523 
Alex G. Sim*

NASA Ames Research Center

Dryden Flight Research Facility Edwards, California

\section{Abstract}

A successful manned, low-speed, controlled deep stall flight research program was conducted at NASA Ames Research Centex's Dryden flight Research Facility. piloting techniques were established that enabled the pilot to attain and stabilize on an angle of attack in the $30^{\circ}$ to $72^{\circ}$ range. A flight-determined aerodynamic data base was established for angles of attack as high as $72^{\circ}$. Poor lateral-directional flying qualities were encountered at angles of attack above $60^{\circ}$. Insight into the high-angle-of-attack lateral-directional dynamics was gained through a basic root-locus analysis.

\section{Nomenclature}

Al1. data are referenced to the body axis and a center of gravity $(\mathrm{cg})$ of $0.4 \overline{\mathrm{c}}$. Flight $\mathrm{cg}$ was either at $0.284 \overrightarrow{\mathrm{C}}$ or $0.33 \overrightarrow{\mathrm{C}}$.

\begin{tabular}{|c|c|}
\hline AGL & above ground level \\
\hline $\mathrm{C}_{\mathrm{l}}$ & primaxy roll damping parameter, per rad \\
\hline$C_{\ell_{B}}$ & effective dihedral parameter, per deg \\
\hline $\mathrm{C}_{\ell} \mathrm{a}_{\mathrm{a}}$ & primary roll control parameter, per deg \\
\hline $\mathrm{C}_{\mathrm{m}_{\mathrm{q}}}$ & pitch damping parameter, per rad \\
\hline $\mathrm{C}_{\mathrm{m}_{\alpha}}$ & $\begin{array}{l}\text { longitudinal static stability parameter, } \\
\text { per deg }\end{array}$ \\
\hline$c_{n_{r}}$ & primary yaw damping parameter, per rad \\
\hline$c_{n_{\beta}}$ & directional stability parameter, per deg \\
\hline$c_{n} \delta a$ & yaw due to aileron parameter, per deg \\
\hline $\overrightarrow{\mathbf{c}}$ & reference chord \\
\hline $\operatorname{cg}$ & center of gravity \\
\hline $\mathrm{Ix}$ & rolling moment of inertia \\
\hline $\mathrm{Iz}$ & yawing moment of inertia \\
\hline MMTE3, 5 & $\begin{array}{l}\text { modified maximum likelihood estimation } \\
\text { program, version } 3 \text { or } 5\end{array}$ \\
\hline $\mathrm{p}$ & roll rate \\
\hline q & pitch angular acceleration \\
\hline RPV & remotely piloted vehicle \\
\hline$x$ & yaw rate \\
\hline
\end{tabular}

TEU

$B / \delta \mathrm{r}$

$\phi / \delta \mathrm{a}$ trailing-edge-up sideslip-to-rudder transfer function bank angle-to-aileron transfer function

\section{Introduction}

During september and october 1983, 20 flights were conducted into the deep stall flight regime using a modified SGS 1-36 sailplane. Low-speed aerodynamic characteristics were obtained in the $30^{\circ}$ to $72^{\circ}$ angle-of-attack range (deep stall). of particular interest were the stability and control parameters, the trim data, and the pilot technique required to safely enter and exit the deep stall. flight regime. This paper will present a summary of the piloting techniques and stability and control results typical of an optimized low-speed vehicle. It is cautioned that results may not be applicable to the long nose designs typically used for high-speed flight.

The controlled deep stall maneuver has been used throughout aviation history. The 1902 wright glider had a poststall "parachute" mode that was used as an emergency landing techniquel. In recent years, the Kasperwing Ultralight ${ }^{2}$ has demonstrated a "vortex mush" flight mode. Model airplanes have used a stabilator "dethermalizer" 3 as a way of inducing a stabilized deep stall and then a recovery. In recent years, Dynamic Engineering Incorporated has expanded on the concept by using power with deep stall to achieve "supernormal" flight". Although many of the present military fighter configurations do have controllable flight at high angles of attack, these configurations are not representative of an optimized low-speed design.

There were two specific objectives of NASA's controlled deep stall program: (1) to document the flight-determined aerodynamics and correlate these data with wind tunnel results; and (2) to demonstrate the feasibility of manned, controlled deep stall flight by refining the piloting techniques needed to safely transition into, maneuver in, and recover from deep stall.

Possible future applications of the deep stall flight mode include: (1) emergency recoveries from spins or spiral dives in instrument flight conditions; (2) near vertical descents in areas of restricted lateral maneuvering; (3) safe recoveries of long-winged, high-altitude remotely piloted vehicle (RPV) aircraft through turbulent intermediate altitudes; and (4) precision recoveries of RPVs when used in conjunction with a retrorocket landing system.

\section{Vehicle}

The vehicle chosen for the controlled deep stall experiment was the Schweizer SGS 1-36 sprite sailplane. It is a single-seat, T-tail design 
that is commercially used as an advanced sailplane trainer (Fig. 1). It is primarily of aluminum fabrication which allowed for straightforward modification of the horizontal tail, longitudinal control system, and cockpit area. To maintain adequate longitudinal control authority, the entire horizontal tail (stabilator) was made movable through a 0 to 70 degree trailing-edge-up (TEU) position and was activated by a lever mounted on the left side of the cockpit. Elevator, rudder, and aileron control remained relatively unchanged. The cockpit area was significantly modified to enhance pilot egress.

The instrumentation system consisted of a $28-$ channel, 10-bit, pulse code modulation system and was the minimum system necessary to conduct the aerodynamic analysis and ensure safety of flight. Air data were obtained through a noseboom that had a self-aligning pitot static head. Data were telemetered to a ground control facility and were monitored real time.

\section{Deep Stall Flight}

The concept of controlled deep stall flight is illustrated in Fig. 2. A condition exists where the wing is fully stalled while the tail is unstalled and somewhat aligned with the airstream to provide good control effectiveness.

An example of a deep stall maneuver is shown in Fig. 3. It shows the entry into the stall, the stabilized deep stall area, and the recovery from the deep stall. On a typical test flight, the vehicle was towed to $8500 \mathrm{ft}$ above ground level (AGL) and released. Once stabilized, the vehicle was decelerated to near-stall airspeed using the elevator (not shown). The technique the pilot used to enter deep stall was to firmly position and then manually hold the stabilator at the ground adjustable stops $\left(30^{\circ}, 40^{\circ}, 50^{\circ}\right.$, or $\left.60^{\circ}\right)$. The total time required to position the stabilator control and achieve deep stall was about $2 \mathrm{sec}$. It was necessary to enter deep stall rapidly to avoid lingering in the poststall (spin) transition area. The transition area, Fig. 4, is characterized by large asymmetries in the lateral-directional forces and moments that are coupled with an aerodynamic unsteadiness. On higher aspect ratio vehicles, the transition area is initiated by an asymmetric wing stall. Note that on long-nosed designs, the nose vortices often dominate the poststall aerodynamics. on the test vehicle, it was not possible to stabilize in the transition area even though significant control effectiveness was available.

After the rapid, but generally smooth, transition to deep stall, the vehicle would quickly stabilize with a near-zero pitch angle. The angle of attack would stabilize between $30^{\circ}$ and $72^{\circ}$, depending on the stabilator and elevator positions. Descent rate would stabilize around $4000 \mathrm{ft} / \mathrm{min}$, which yielded about $1 \mathrm{~min}$ of data in deep stall. First, a trim point was attained followed by elevator, rudder, and aileron doublets. These doublets were used for the postflight parameter estimation analysis. The pilot would then perform a number of maneuvers to assess vehicle flying qualities. All deep stall maneuvering was terminated above $5000 \mathrm{ft}$ AGL.
Recovery was initiated by using the stabilator to lower the angle of attack (between $25^{\circ}$ and $30^{\circ}$ ) to the transition area. Although the actual angle of attack was not displayed in the cockpit, the transition area was sensed by the pilot from both the mild tail buffet (due to wing wake) and the aerodynamic unsteadiness. Upon encountering the transition area, the stabilator was rapidly moved to zero - the baseline configuration. During recovery, 300 to $500 \mathrm{ft}$ of altitude were used while the airspeed typically increased from 38 to 55 knots. When the recovery was accomplished in this manner, it was very positive and docile.

During the stabilized portions of the deep stall, the presence of a slow lateral-directional oscillation degraded the flying qualities, particularly at the very high angles of attack. Lateraldirectional handing qualities were further degraded by the unstable hinge moments for both aileron and rudder. The reasons for the oscillations will be discussed in the dynamics section of this paper. The longitudinal flight characteristics were generally satisfactory to attain the desired angle of attack.

Aerodynamic Data

\section{Predicted Data}

A basic $32-\mathrm{hr}$ wind tunnel test was conducted in the NASA Langley 30 by 60 wind tunnel ${ }^{5}$ using a 0.25 -scale modified free-flight model. To limit model loading, testing was done at a low dynamic pressure which yielded a Reynolds number of 180,000 based on mean wing chord. This low Reynolds number is generally considered to be on the high side of the subcritical range. However, the flight vehicle operates at about 10 times the model's Reynolds number. Data from other studies (Fig. 5) have shown that representative trends can be obtained by testing at subcritical Reynolds numbers for values of drag and pitching moment; lift is representative only at high and low angles of attack. values for lift are not representative in the transition area. However, note that these wind tunnel data are representative of the type of results that would be obtained from small-scale free-flight, drop model, or spin tests. The damping derivatives used as predictions were estimated by using a combination of computational methods ${ }^{6}$, hand methods, and considerable engineering judgment.

\section{Parametex Analysis}

Parameter analysis was conducted by using a later version of the maximum likelihood technique ${ }^{7}$. The computer program associated with this technique, MMLE5, and its earlier versions are widely accepted as some of the best techniques available for estimating stability and control derivatives. However, this deep stall analysis was the first to use the technique to angles of attack as high as $72^{\circ}$.

The linearized three-degree-of-freedom equations of motion used (as default) in MMLE5 include the inertial-coupling terms by using measured data for the angular rates. An example is that the interialcoupling term $\mathrm{rp}(\mathrm{Iz}-\mathrm{Ix})$ from the $\dot{q}$ equation uses measured values for $r$ and $p$. High angular rates 
were of ten present in deep stall because of low lateral-dixectional damping. A longitudinal maneuver could not be accomplished independent of lateral-directional motion and vice versa. Thus the inertial coupling terms were significant.

Longitudinal parameters. Insight into the nature of the generally difficult longitudinal analysis can be gained by looking at a pitch pulse maneuver at $63^{\circ}$ angle of attack (Fig. 6). The solid line is measured flight data, and the dashed line represents the MMLE5's computed response to only the elevator input. Although the pilot rigidly held the stabilator control lever at the cockpit stop, stabilator motion still occurred because of elasticity in the stabilator's mechanical push-rod control system. The close phasing between the elevator and the stabilator precluded modeling both these controls as unknowns in the parameter analysis.

Another anomaly with the high-angle-of-attack longitudinal data was the presence of a $2.4 \mathrm{~Hz}$ structural mode, particularly evident in pitch rate (Fig. 6). Most of the maneuvers that were successfully analyzed contained a much lower level of structural contamination than is present in Fig. 6. Nine of the nineteen high-angle-of-attack longitudinal maneuvers yielded reasonable derivative results. An example of these results and the analysis results at low angles of attack is shown for longitudinal static stability parameter $\left(\mathrm{C}_{\mathrm{m}_{\alpha}}\right)$ and pitch damping parameter $\left(\mathrm{C}_{\mathrm{m}_{\mathrm{q}}}\right)$ in Fig. 7. At the low angles of attack, the analysis was degraded by an overdamped vehicle response. Although the longitudinal parameter results are characterized by high levels of scatter, they do substantiate the general levels of the longitudinal parameters. The bounds shown in Fig. 7 are uncertainty levels, and are only shown on the plot when they are larger than the symbol size.

Lateral-Directional Parameters. The lateraldirectional maneuver in Fig. 8 illustrates several key points that apply to all of the high-angle-ofattack maneuvers. The traditional aileron and rudder doublet set maneuver was found to be adequate for parameter estimation at high angles of attack. The lateral-directional dynamics were near neutrally stable causing the vehicle to generally "wallow" around with about $20^{\circ}$ of bank and sideslip angles. with regard to the bank and sideslip angles, the magnitude of the maneuver is larger than desired considering that small perturbation assumptions have been made. The measured sideslip was not used in the analysis, and is only displayed on the plot to give a general impression of the maneuver.

For near neutral stability systems, MMLES often has convergence problems if the starting estimates are not near the true value. It was discovered early in the program that the lateraldirectional predicted data wexe not close enough to allow convergence. The initial maneuvers that were analyzed required considerable adjustments in the starting values. These adjustments were aided by a program option that was used to place a heavy weighting on the starting values. Typicaliy this weighting was removed after the first four to five iterations, allowing for an unbiased convergence in nine to thirteen total iterations.
The lateral-directional static stability parameters, $C_{\ell_{\beta}}$ and $C_{n_{\beta}}$, shown in Fig. 9, are lower than predicted at the higher angles of attack. Although both parameters are at an acceptable level, a less negative value for the effective dihedral parameter, $C_{\ell_{\beta}}$, would enhance handling qualities. The large discrepancy in $\mathrm{C}_{\ell_{\beta}}$ between the predictions and flight data is not fully understood, although other wind tunnel results have shown that large changes in wing dihedral do not have a significant effect on $C_{\ell_{\beta}}$ at high angles of attack.

The primary lateral-directional damping parameters, $C_{l_{p}}$ and $C_{n_{Y^{\prime}}}$ are presented in Fig. 10. The roll damping parameter, $C_{l_{p^{\prime}}}$ is slightly unstable (positive value) at angles of attack greater than about $50^{\circ}$. The primary yaw damping parameter, $c_{n_{r}}$, remains at a stable (negative) value.

The aileron control parameters in Fig. 11 show the primary roll control parameter $\left(\mathrm{C}_{\ell_{\delta a}}\right)$ to decrease at the higher angles of attack but to remain at a small positive value. However, the yaw due to aileron parameter $\left(\mathrm{C}_{\mathrm{n}_{\delta}}\right)$ is proverse (positive) at low angles of attack and goes adverse (negative) at the higher angles of attack. The ratio of $C_{n \delta a}$ to $C_{\ell_{\delta a}}$ becomes a relatively large negative value for angles of attack greater than $60^{\circ}$. With this ratio negative, and with a negative value for $C_{\ell_{\beta}}$ (Fig. 9), a roll reversal can occur even though the value for $C_{\ell}$ remains positive.

\section{Deep Stall Dynamics}

To gain insight into the basic flying qualities in deep stall; a root-locus analysis was conducted at $50^{\circ}$ and $65^{\circ}$ angle of attack using the final flight-determined aerodynamic data.

The pilot's control of bank angle using aileron was represented by modeling the pilot as a variable gain in a bank angle to aileron feedback loop. The resulting root locus (Fig. 12) illustrates $50^{\circ}$ and $65^{\circ}$ angle of attack. However, at $50^{\circ}$ angle of attack, the pilot model was able to stabilize the system using less than 0.5 gain; at $65^{\circ}$ angle of attack, the system remained slightly unstable regardless of pilot model gain used. A gain of about 0.5 is considered to be the maximum that a pilot can induce into the system. With the very low levels of aileron control effectiveness, a 0.5 gain does little to modify the basic openloop characteristics, especially at the very high angles of attack.

The pilot's control of sideslip angle using rudder was also represented by modeling the pilot as a variable gain. The sideslip-to-rudder locus (Fig. 13) shows that the pilot model is able to slightly stabilize the dutch-roll mode at $50^{\circ}$ angle of attack, but aggravates the dynamics at the higher $65^{\circ}$ angle of attack.

Considering data in Figs. 12 and 13, it is apparent that at high angles of attack, the airplane tends to "wallow" axound. Furthermore, the 
pilot has negligible lateral-directional control at the very high angles of attack. In flight, these oscillations were generally limited in amplitude to about $\pm 20^{\circ}$ of bank angle and occurred within about a 4-sec period. For the $50^{\circ}$ angle-ofattack condition, the pilot quickly learned a technique (proper lead and lag) to damp the oscillations. At lower angles of attack $\left(30^{\circ}\right.$ and $\left.40^{\circ}\right)$, the lateral-directional dynamics were not generally a primary concern because of the higher damping and higher control effectiveness. At angles of attack above $60^{\circ}$, the pilot was not able to effectively damp the lateral-directional oscillations.

\section{Conclusions}

The following conclusions can be drawn from the results of the manned, low-speed, controlled deep stall flight research program.

1. Piloting techniques were established that allowed the pilot to attain and stabilize on an angle of attack in the $30^{\circ}$ to $72^{\circ}$ range.

2. A flight-determined aerodynamic data base was established for angles of attack as high as $72^{\circ}$.

3. Poor lateral-directional flying qualities were encountered at angles of attack above $60^{\circ}$.

4. Insight into the high-angle-of-attack lateral-directional dynamics was gained through a basic root-locus analysis.
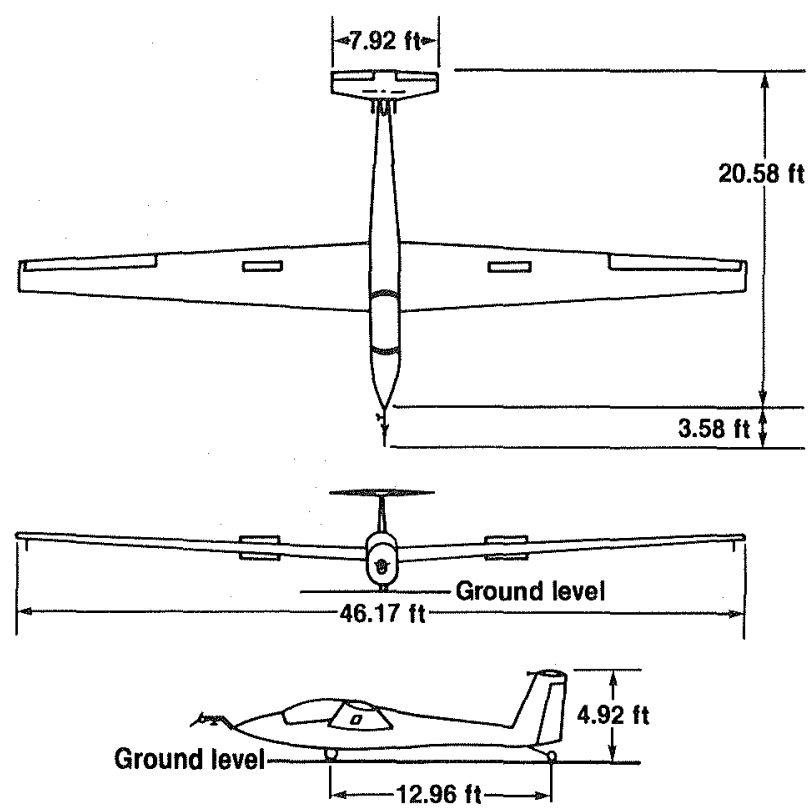

Fig. 1 SGS 1-36 Sprite sailplane.

\section{References}

lCombs, Harry, "Kill Devil Hill," Houghton Mifflin Co., 1979.

2 Horne, Thomas A., "Redemption at Issaquah," AOPA Pilot, vol. 24, no. 5, 1981, pp. 57-60.

${ }^{3}$ Goldberg, Carl, "Bring Them Down Safely," Model Airplane News, 1943, pp. 18-20.

${ }^{4}$ Strom, Thomas H., and Alford, William J., "Flight at Supernormal Attitudes," SAE Paper 821469 , Oct. 1982.

${ }^{5}$ paulson, John $\mathrm{W}$. , "Low speed Wind Tunnel Investigation of a 0.25 -Scale Model similar to the Schweizer SGS 1-36 Sprite Sailplane," Dynamic Engineering, Inc. Technical Report D-086, 1983.

6Iamar, John E., and Gloss, Blair B.," "Subsonic Aerodynamic Characteristics of Interacting Lifting Surfaces with Separated Flow Around Sharp Edges predicted by a vortex-Lattice Method," NASA TN D-7921, 1975.

${ }^{7}$ Maine, Richard E., and Iliff, Kenneth W. "User's Manual for MMLE3, A General FORTRAN Program for Maximum Likelihood Parameter Estimation," NASA TP-1563, 1980.

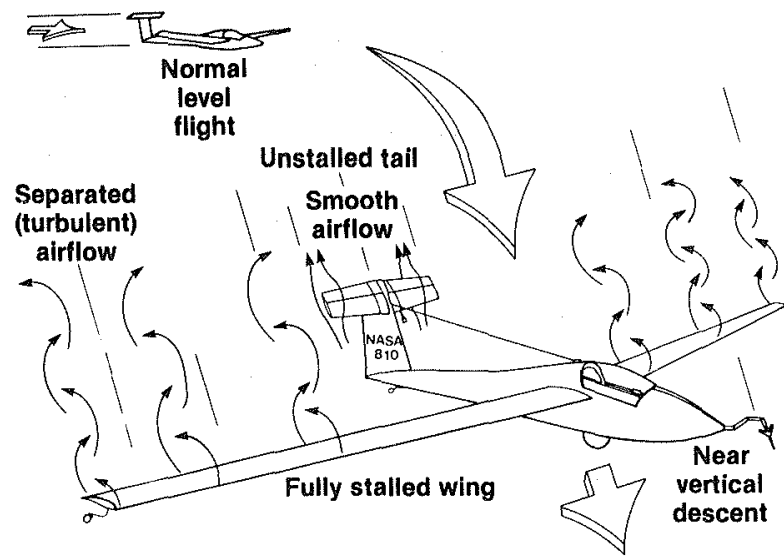

Fig. 2 Basic controlled deep stall concept. 

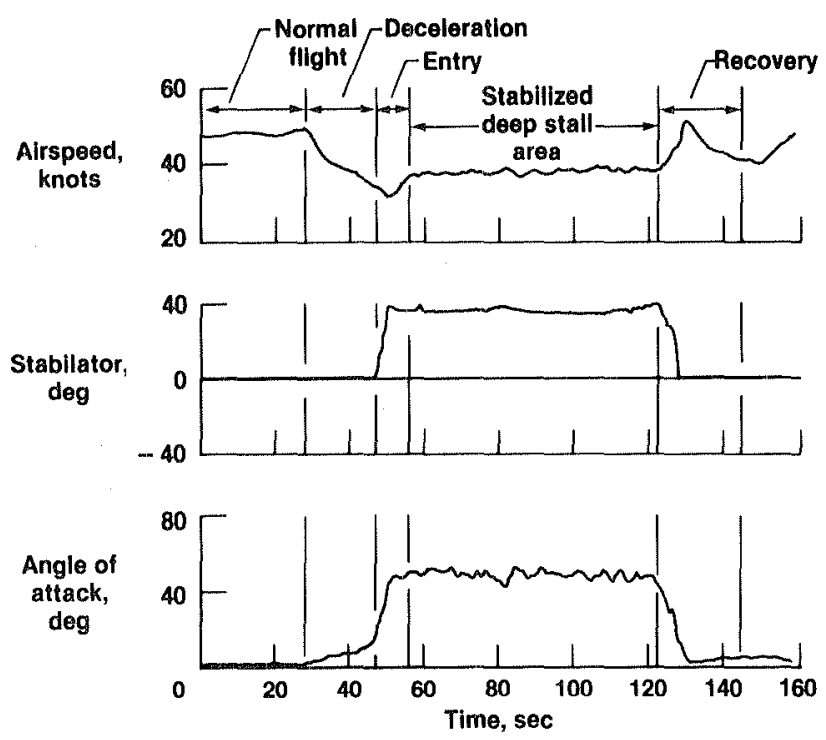

Fig. 3 Deep stall maneuver.

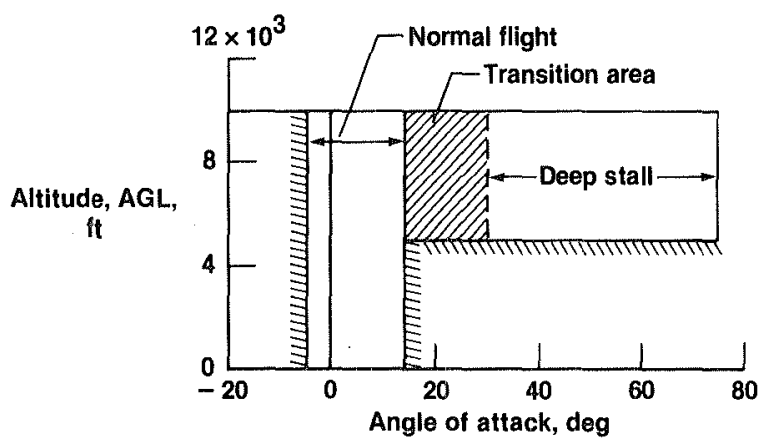

Fig. 4 Flight envelope.
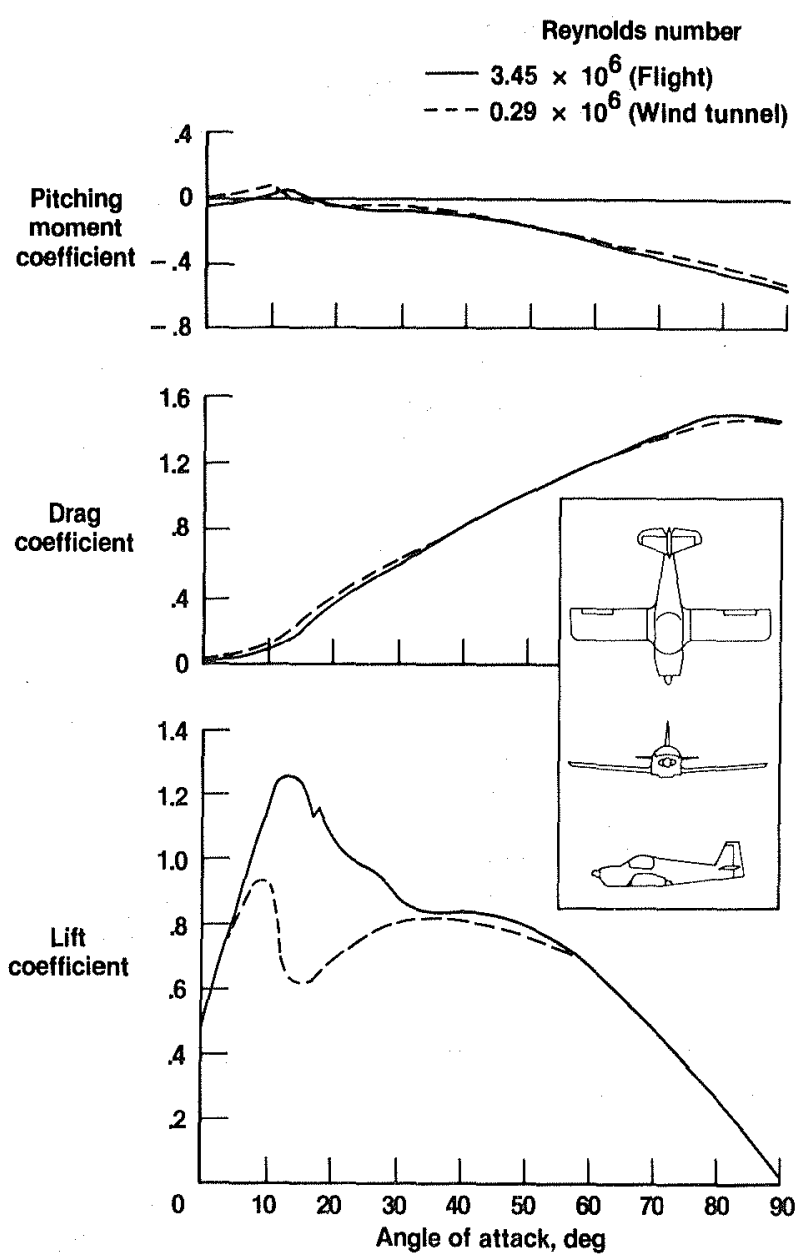

Fig. 5 Effect of Reynolds number on longitudinal characteristics of a light plane. 

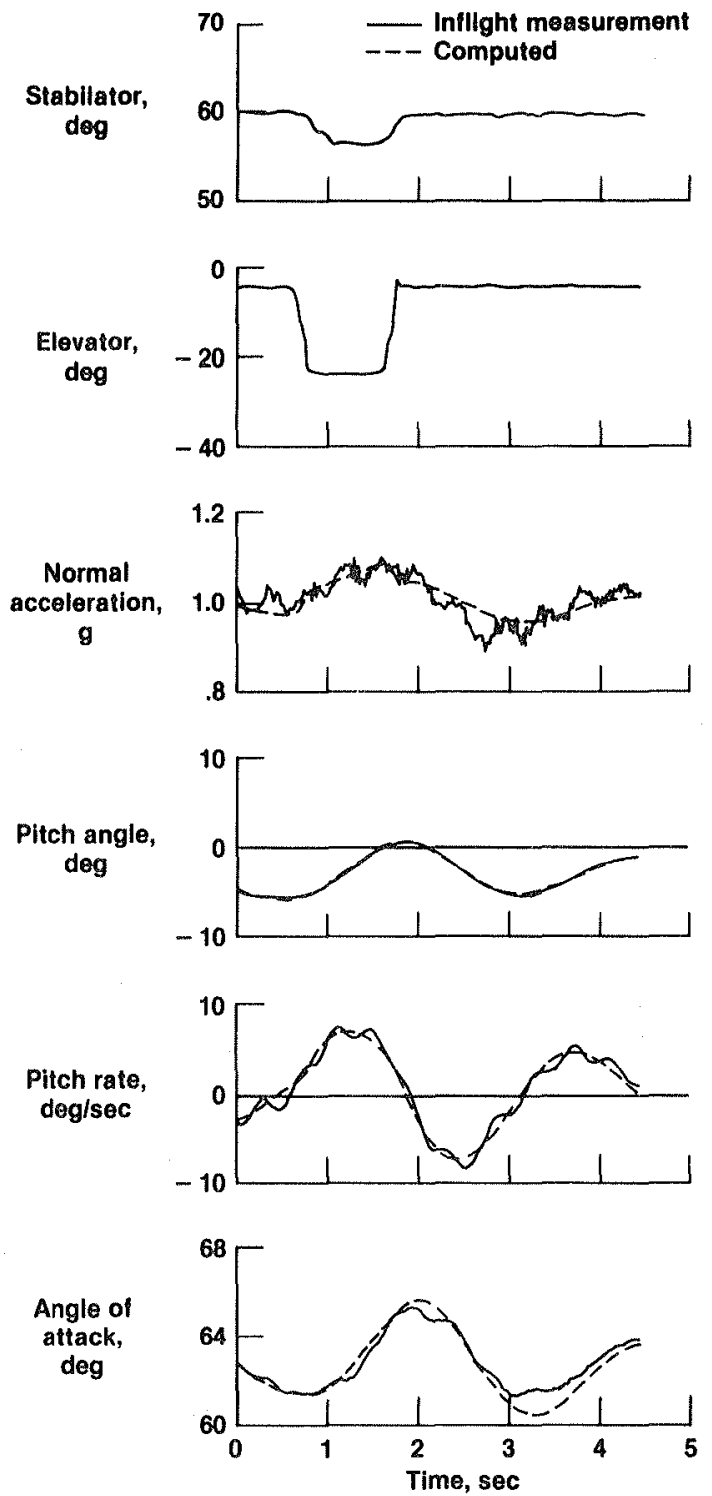

Fig. 6 Longitudinal maneuver at $63^{\circ}$ angle of attack.
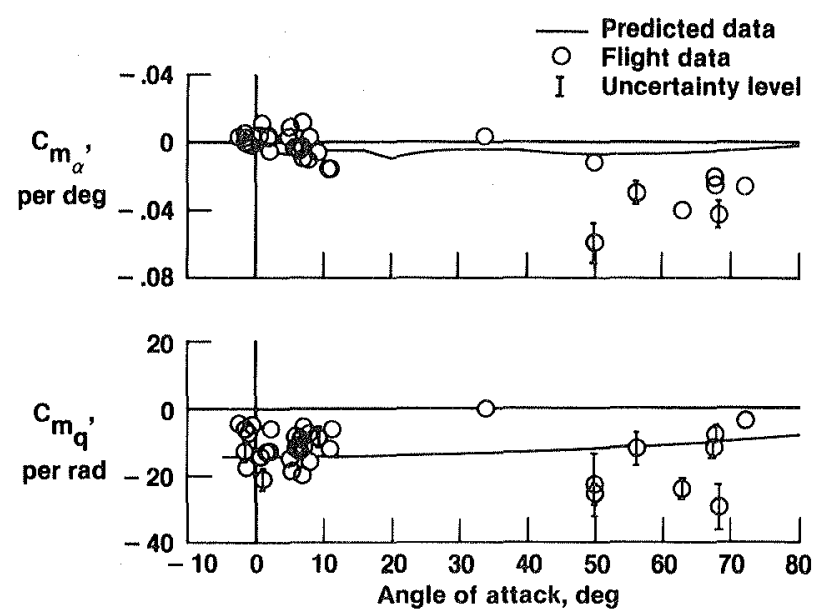

Fig. 7 An example of the longitudinal parameter results.
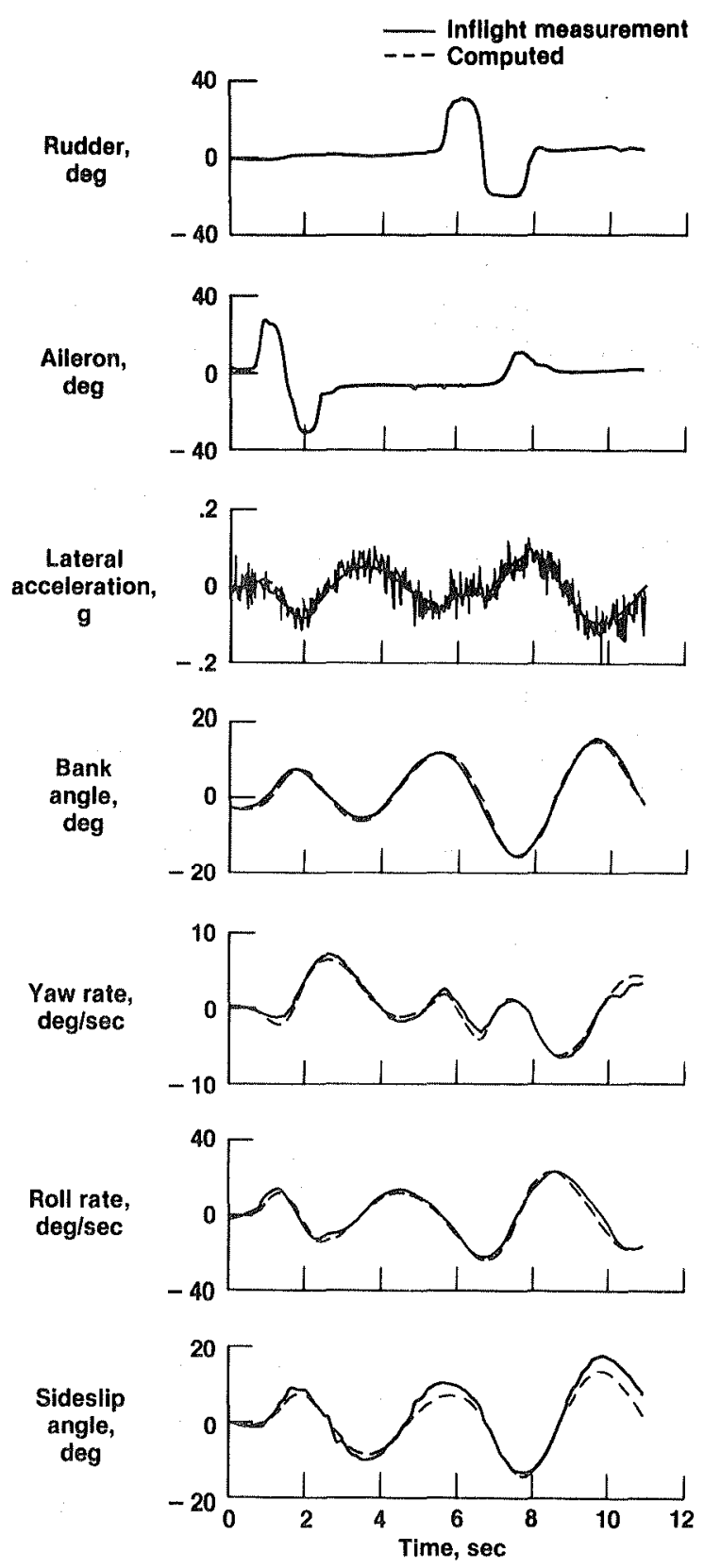

Fig. 8 Lateral-directional maneuver at $48^{\circ}$ angle of attack. 

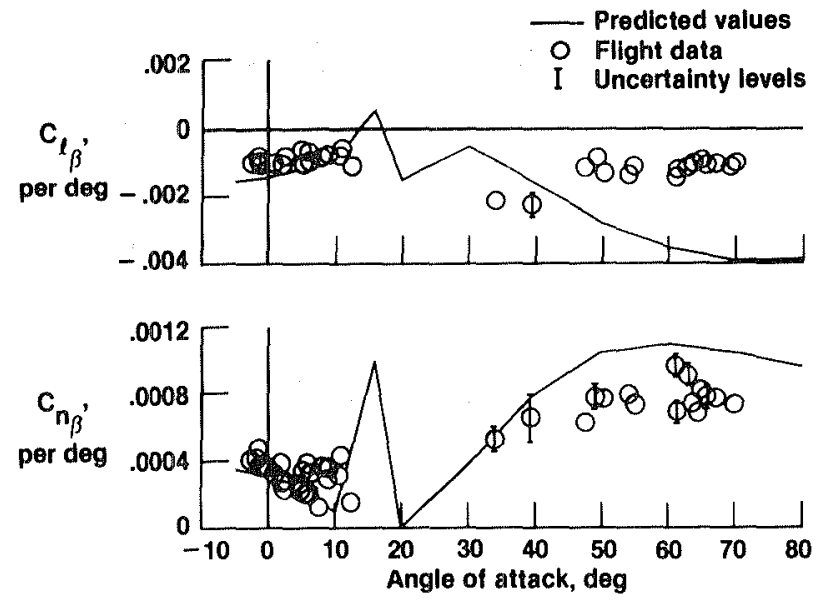

Fig. 9 Lateral-directional static stability parameters.
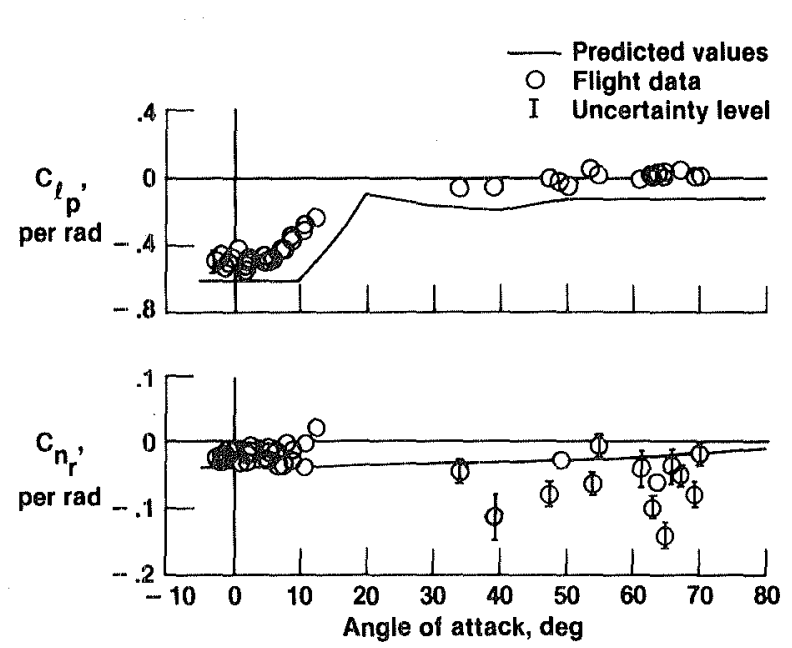

Fig. 10 Lateral-directional damping parameters.
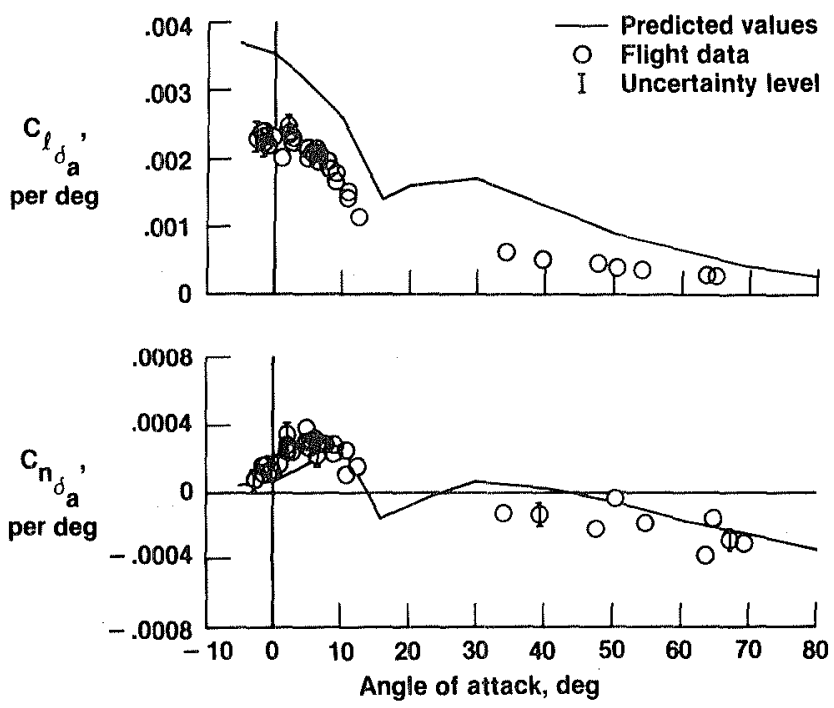

Fig. 11 Aileron control parameters.

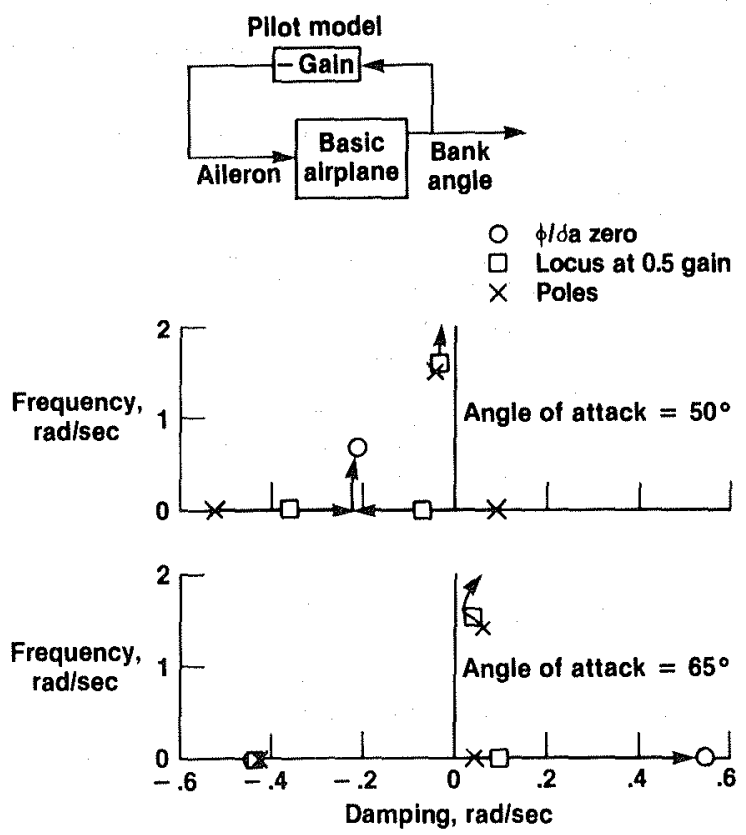

Fig. 12 Root locus for $\phi / \delta a$ at angles of attack of $50^{\circ}$ and $65^{\circ}$.
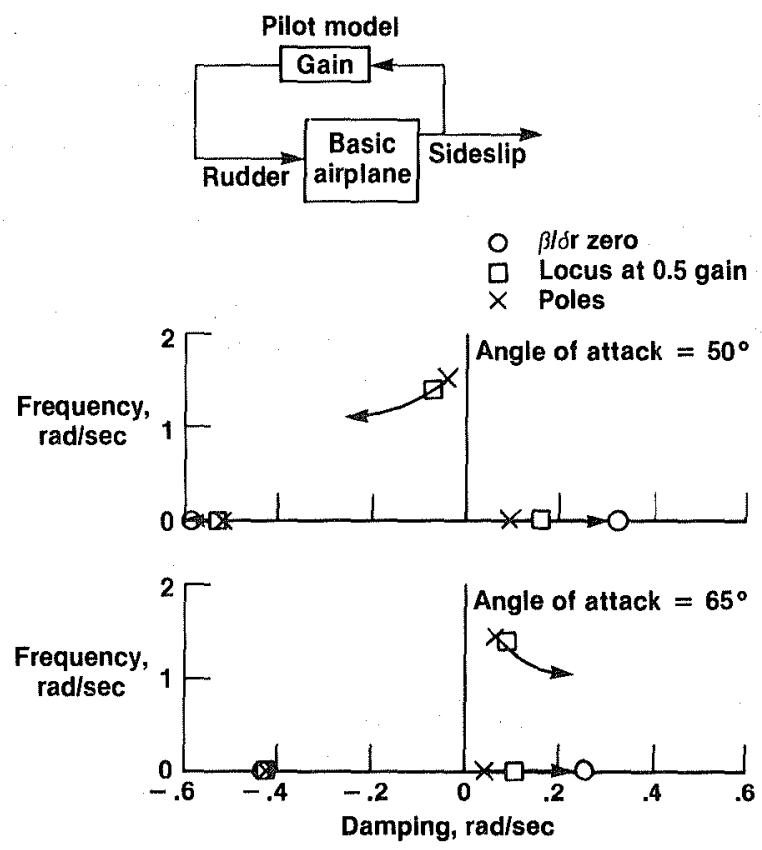

Fig. 13 Root locus for $\beta / \delta x$ at angles of attack of $50^{\circ}$ and $65^{\circ}$. 


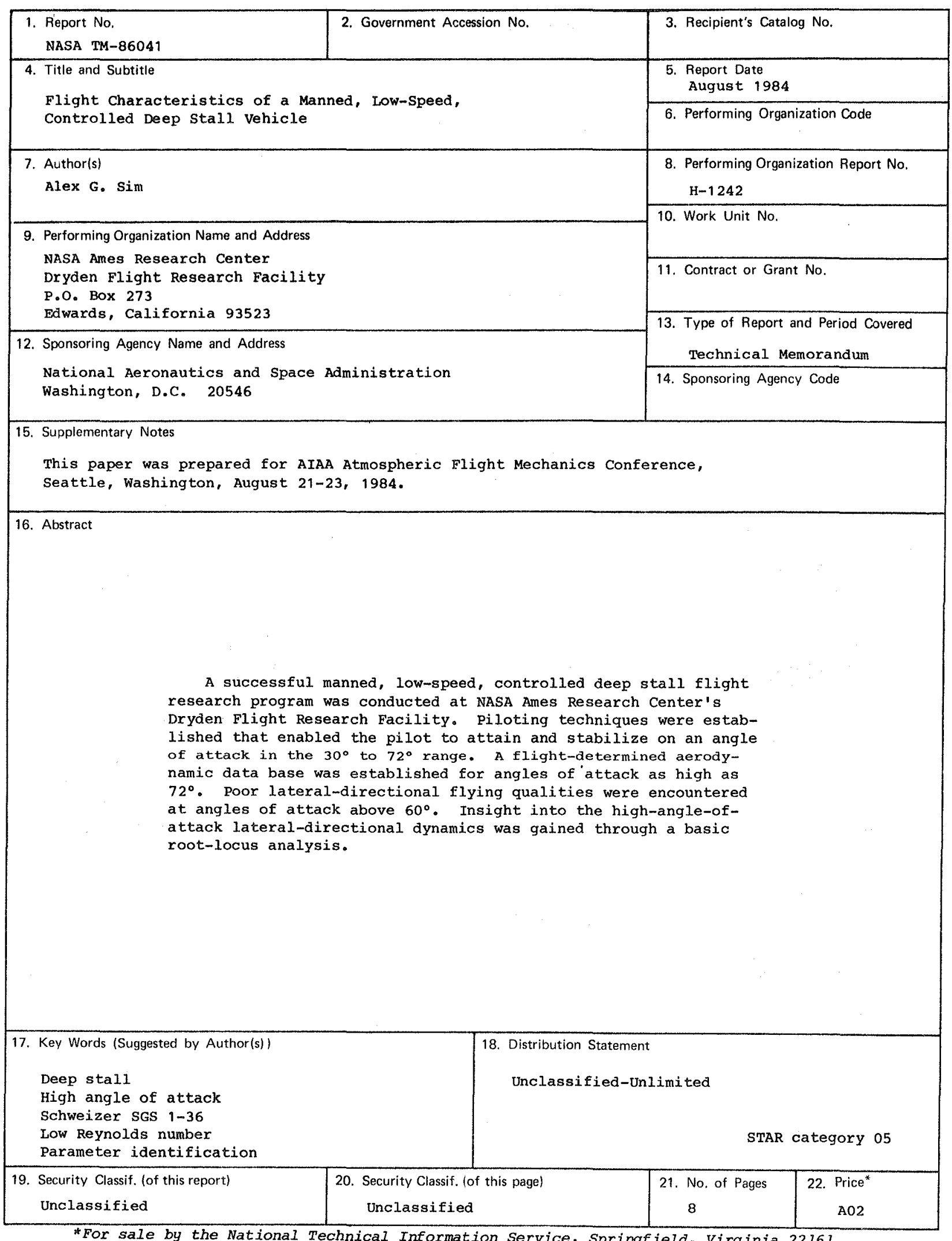

*For sale by the National Technical Information Service, Springfield, Virginia 22161. 
End of Document 